\title{
Biomedical Titanium Alloy Prepared by Additive Manufacturing: Effect of Pro- cessing on Tribology
}

Michaela Roudnicka ${ }^{1,2}$, Frantisek Bayer ${ }^{1}$, Alena Michalcova ${ }^{1}$, Jiri Kubasek ${ }^{1}$, Enas Ghassan Hamed Alzubi ${ }^{1}$, Dalibor Vojtech ${ }^{1}$

${ }^{1}$ Department of Metals and Corrosion Engineering, Faculty of Chemical Technology, University of Chemistry and Technology Prague. Technicka 5, 16628 Prague 6, Czech Republic. E-mail: michaela.roudnicka@vscht.cz, bayerf@vscht.cz, alena.michalcova@vscht.cz,kubasekj@vscht.cz,vojtechd@vscht.cz

${ }^{2}$ Institute of Physics of the Czech Academy of Sciences. Na Slovance 1999/2, 18221 Prague 8, Czech Republic.

In the production of a new generation of customized implants, additive manufacturing (AM) is a hot topic. A titanium-based alloy, Ti6Al4V, is one of the most used materials for such applications with regard to its excellent biocompatibility and high mechanical properties which provide it with the capability to bear physiological loads. However, its resistance to wear is rather poor which might cause undesirable loosening of wear particles or even implant failure. Therefore, enhancing wear resistance is desirable. Thanks to a distinctive principle and rapid cooling, AM is known to be able to enhance mechanical properties. In this paper, we thus discuss tribological properties in direct relation to microstructures resulting from AM. We reveal the finest microstructural details of Ti6Al4V alloy prepared by different techniques of AM and discuss also the effect of heat treatment. Complex characterization including transmission electron microscopy, hardness measurement and ball-on-plate wear tests showed a mild contribution of AM to wear resistance of the Ti6Al4V alloy compared to the conventionally produced alloy.

Keywords: additive manufacturing, Ti6Al4V, TEM, tribology

\section{Introduction}

Titanium-based alloys are very attractive for many industrial sectors owing to their unique physical, mechanical, chemical and biological properties. However, due to their electron configuration, crystal structure and low thermal conductivity, titanium and its alloys are characterized by poor tribological behaviour. They show high and unstable friction, severe adhesive wear, low resistance to abrasion, susceptibility to fretting wear and a strong tendency to seize. This problem can be overcome by surface engineering or the poor wear resistance can be improved to some extent by changing the alloy structure [1].

Titanium alloys are particularly prone to adhesive wear and their resistance to abrasive wear is neither very good as they are relatively soft. Adhesive wear occurs when a titanium surface is in contact with most engineering material surfaces in motion. Strong adhesion of titanium is related to its electron structure. Junction is easily formed between contact surfaces. When the acting force exceeds the adhesive strength, junction ruptures, a part of the material is torn and deformed by the following slip. The torn particles of the material between the moving surfaces then act abrasively. Operations such as surface thermo-chemical treatment (e.g. nitriding), surface recrystallization or heat treatment that increase hardness and so resistance to abrasive wear are not very effective in improving the resistance to adhesive wear because these operations do not change the nature of titanium. However, adhesive wear is also influenced by ductility. Therefore, operations which reduce ductility decrease the tendency to adhesive wear [1].

Additive manufacturing (AM) of titanium and its alloys is nowadays gaining a lot of attention, especially in the production of sophisticated parts, because of its capability to provide complex structures with high resolution relatively simply. Such application area is mainly the production of biomedical implants where titanium ensures excellent biocompatibility, corrosion resistance and sufficient mechanical properties for bearing physiological loads while AM provides perfectly fitting implant shapes and structures mimicking the physiological ones. A new generation of customized patient-tailored implants thus arises with the means of AM. Implants can be prepared directly according to the medical scans of a replaced tissue, surface porous structures may allow bone ingrowth and ensure lifetime fixation of the implant, internal porous structures may allow vascularization and nutrients transport etc. [2].

For implant materials which are cyclically mechanically loaded and are in a movable contact with another material (either bone or an artificial metallic, ceramic or polymeric material), such as knee or hip joint replacements, it is very important to resist wear. Not 
only that wear damages the implant device or the adjacent tissue irreversibly and might proceed to such extent that there is a need for reoperation, but it can also burden the biological system with loose abrasive particles that can cause metallosis and many other health issues. There is thus a maximal effort to prevent the wear [3].

Considerable work has already been done in the tribological evaluation of biomedical titanium alloys [4-7]. For example, it has been shown that metastable $\beta$-alloys have lower adhesive wear resistance than $\alpha+\beta$ alloys despite their enhanced strength and hardness. The cause is probably a higher ductility of $\beta$-phase [6]. Not only Suresh et al. [7] showed that the preparation of ultra-fine grained microstructures improve wear resistance. Also, quenching yielding a martensitic microstructure can help enhance tribological properties, e.g. in the case of Ti6Al4V alloy [5]. It is thus clear that alloy microstructure can partially influence its wear behaviour.

AM is known to significantly alter the microstructure of metallic alloys. Extremely rapid cooling, gradual processing of materials in small volumes, complex thermal history due to layer-wise processing and other features inherent to AM give rise to extremely fine microstructures with metastable phases, supersaturated solid solutions, microsegregations, high dislocation densities, significant residual stresses etc. Additively manufactured alloys may thus exert different properties than their conventionally produced counterparts [8-10].

In this paper, we describe the dependency of the wear resistance of Ti6Al4V alloy prepared by two technologies of AM on their specific processing route. We describe detail microstructural features of the alloy (1) prepared by selective laser melting (SLM), (2) prepared by SLM and further processed by hot isostatic pressing (HIP), (3) prepared by electron beam melting (EBM), and discuss their influence on hardness and specific wear rate.

\section{Methods and Materials}

\subsection{Studied materials}

Material presented in this paper is a Ti6Al4V alloy with extra low interstitials (referred to as Ti grade 23) which composition is given by ASTM F136 [11] standard. It was prepared by two techniques of AM, selective laser melting (SLM) and electron beam melting (EBM). SLM wan done using an M2 cusing ConceptLaser machine. Processing parameters were reported previously in [12]. This material was studied in its asbuilt state ("SLM") and also after the application of hot isostatic pressing at $920^{\circ} \mathrm{C}$ with a duration of $2 \mathrm{~h}$ ("SLM-HIP"). Detail study focusing on the effect of HIP on porosity and mechanical properties was published in [13]. EBM was accomplished with an Arcam
Q10 machine ("EBM"). Processing parameters were reported in [12] too. A commercially purchased hotworked bar was used as a reference.

\subsection{Microstructure characterization}

For microstructure characterization, the samples were cut perpendicular to the building direction (in the plane of layer deposition). The metallographic sections were ground on $\mathrm{SiC}$ papers and polished on diamond suspensions. Final polishing in silica suspension was appended by the chemical action of hydrogen peroxide (mixture ratio 3:1). For the observation by a scanning electron microscope (SEM) TESCAN VEGA-3 LMU, microstructures were visualized by etching in Kroll's reagent. ImageJ was used for image analysis. For the observation by a transmission electron microscope (TEM) Jeol 2200FS, disks of $3 \mathrm{~mm}$ in diameter were punched from $60 \mu \mathrm{m}$ thin foils and polished by ionized Ar in Gatan PIPs. Energy dispersive X-ray spectroscopy (EDS) in TEM was accomplished to determine the chemical composition of constituting components. Phase composition was determined by X-ray diffraction (PANalytical X'Pert PRO, High Score Plus software).

\subsection{Hardness and wear tests}

Vickers hardness was measured on a semi-automatic hardness tester Future-Tech FM-700 with 1 kg load and $10 \mathrm{~s}$ holding time. Fifteen measurements were done for each material. To study wear resistance, a ball-on-plate tribometer by TRIBOtechnic equipped with $6 \mathrm{~mm}$ corundum ball was used. Measurements were done on air at laboratory temperature according to the ISO 7148 standard. To provide a sufficiently large area for the reciprocating sliding measurement, plates were prepared from the round samples parallel to the building direction and wear was measured in the building direction. Hardness was measured on these plates as well to provide direct correlation with the results of the wear tests. Prior to wear testing, the plates were polished, rinsed with water and ethanol, and dried. The parameters of the wear tests were: normal load $F_{N}=1 \mathrm{~N}$ or $5 \mathrm{~N}$, a sliding speed of $10 \mathrm{~mm} \mathrm{~s}^{-1}$, a stroke length $l=5 \mathrm{~mm}$, the total distance $L=20 \mathrm{~m}$. Specific wear rate (SWR) was calculated according to the following equation:

$$
S W R=\mathrm{S} \cdot l \cdot F_{N}^{-1} \cdot L^{-1}
$$

where $S$ is the area of the profile of a wear track measured by a contact profilometer with a high resolution of $7.55 \mathrm{~nm}$. Wear tracks were subsequently documented by SEM in the regime of secondary electrons (SE) and back-scattered electrons (BSE). EDS maps were constructed to visualize the distribution of individual elements within the wear tracks. 


\section{Results and Discussion}

In the present work, the tribological behaviour of Ti6Al4V alloy is compared for different production routes and is directly correlated with the microstructural features yielded by different processing, including two techniques of powder bed additive manufacturing possibly supplemented by HIP. A conventionally produced hot-worked alloy serves as a reference to all the studied states.

\subsection{Microstructure}

Ti6Al4V alloy is an $\alpha+\beta$ Ti-alloy due to the $\alpha$-stabilizing effect of $\mathrm{Al}$ and $\beta$-stabilizing effect of $\mathrm{V}$. Both close-packed hexagonal (hcp) crystal structure, referred to as $\alpha$-phase, and body-centered (bcc) crystal structure, referred to as $\beta$-phase, are present at room temperature in the equilibrium state. However, the formation of Ti6Al4V microstructure depends highly on cooling rates and thermal cycles to which the alloy is subjected during processing. When this alloy is slowly cooled from the $\beta$ region, $\alpha$-phase starts to form below the transformation temperature which is $995 \pm 5^{\circ} \mathrm{C}[14]$. The $\alpha$-phase grows in the form of plates on specific planes in $\beta$-grain. There are six sets of nonparallel growth planes. The basal close-packed plane of $\alpha$-phase is parallel to one of these. Because of the close atomic matching along the common plane, nucleus of $\alpha$-phase grows relatively slowly in the perpendicular direction than along the plane and so $\alpha$ plates are developed. Such microstructure is referred to as the Widmanstätten microstructure. However, during fast cooling from above the $\beta$-transus temperature, martensitic diffusionless decomposition can take place. Martensite, $\alpha$ or $\alpha$ ”, occurs in needle-like form and occupies the same hcp structure as $\alpha$-phase but oversaturated by atoms of $\beta$-stabilizing $\mathrm{V}$ in substitutional positions. That explains why not such a strong strengthening as for martensite in steels is achieved by this transformation in TiAl6V4 [15]. When treating in the $\alpha+\beta$ region, equiaxed grains of $\alpha$ with intergranular $\beta$ are developed [16].

Both, SLM and EBM are techniques associated with high cooling rates. The cooling rates during SLM are reported to reach $10^{6}-10^{8}{ }^{\circ} \mathrm{C} \mathrm{s}^{-1}[17]$ and for EBM $10^{3}-10^{4}{ }^{\circ} \mathrm{C} \mathrm{s}^{-1}[18]$. Such velocities significantly exceed the limit rate for martensitic transformation (20 ${ }^{\circ} \mathrm{C} \cdot \mathrm{s}^{-1}, 420{ }^{\circ} \mathrm{C} \cdot \mathrm{s}^{-1}$ for complete transformation) so that martensitic transformation occurs when a small amount of alloy powder is melted by laser or electron beam and solidified the very next moment [19]. From this point further, the microstructure development differs for SLM and EBM. During EBM, electron beam is used to preheat every layer up to $600-750{ }^{\circ} \mathrm{C}$ [19]. Keeping the solidified material at this temperature range not only lowers the temperature gradients, resulting cooling rates and thermal stresses associated, but also yield in the martensitic decomposition. While fully martensitic microstructure is preserved in the SLM material, EBM material shows lamellar $\alpha+\beta$ microstructure [12]. Sometimes, martensitic structure can remain in the top layer only. To obtain lamellar $\alpha+\beta$ microstructure and release internal stresses in order to increase ductility of the material, stress-relief annealing is often applied after SLM. Hot isostatic pressing (HIP) is another operation which provides the release of internal stresses and phase transformation although its primary goal is material densification by its plastic deformation achieved by isostatic pressure of an inert gas acting at increased temperature [20].

Figure 1 shows the comparison between the microstructures of the Ti6Al4V alloy in the as-built states after SLM and EBM and SLM after HIP. One-phase martensitic microstructure is clearly distinguishable in Fig. 1a showing as-built SLM state in comparison with the two-phase $\alpha+\beta$ microstructure in Fig. 1b,c. The main difference between the microstructure in SLMHIP state and EBM material is the fineness of $\alpha$-lamellae; $1.9 \pm 0.7 \mu \mathrm{m}$ and $0.6 \pm 0.1 \mu \mathrm{m}$, respectively. Explanation can be found in the different temperature at which the lamellae were formed. The higher temperature of HIP supported the diffusion of $\mathrm{V}$ and so growth of $\alpha$-lamellae. The size of the lamellae in the hot-worked material lies in between $(0.8 \pm 0.3 \mu \mathrm{m})$. Also, the content of $\beta$-phase varies; while $\sim 12 \%$ of $\beta$ phase were detected in SLM-HIP and hot-worked samples, EBM showed its content of up to $\sim 18 \%$.

TEM images in Fig. 2 depict the microstructural details further, make possible to evaluate the thickness of $\alpha^{6}$-needles and give visual information about the internal stresses. Figure 2 a shows a high dislocation density and a significant amount of crystallographic defects in martensitic needles in the as-built SLM state, which suggests that stresses arising during $\beta \rightarrow \alpha^{\prime}$ transformation are accommodated primarily by formation of dislocations. The thickness of martensitic needles ranges tens of nanometers (Fig. 2b). After heat treatment by HIP (Fig. 2c), $\alpha^{6}$-needles transform into $\alpha$-lamellae by expulsion of $\mathrm{V}$ atoms. $\beta$-phase rich in $\mathrm{V}$ is thus formed in the interlamellar spaces. The distribution of constituting elements is clearly seen in TEM-EDS elemental maps in Fig. 3. Compared to $\alpha-$ phase containing $2.4 \pm 0.2$ wt. $\%$ of $\mathrm{V}, \beta$-phase contains $18.3 \pm 1.4$ wt. $\%$ of $V$. Reduced dislocation density in Fig. 2c demonstrates that HIP treatment successfully relieved the residual stresses. Similar microstructure can be observed in case of the EBM as-built state (Fig. 2d). Residual stresses were significantly lowered due to maintaining the material during the whole processing time at the temperature of $740^{\circ} \mathrm{C}$. That agrees with the low dislocation density in Fig. $2 \mathrm{~d}$. The TEM-EDS analysis detected $24.8 \pm 1.3 \mathrm{wt} . \%$ of $\mathrm{V}$ in the $\beta$-phase. Higher content of V compared to the $\beta$ phase in the SLM-HIP state agrees with the phase diagram; the $\beta$-phase formed at the temperature of 740 
${ }^{\circ} \mathrm{C}$ is richer in $\mathrm{V}$ than the $\beta$-phase formed by the decomposition of martensite at $920^{\circ} \mathrm{C}$.

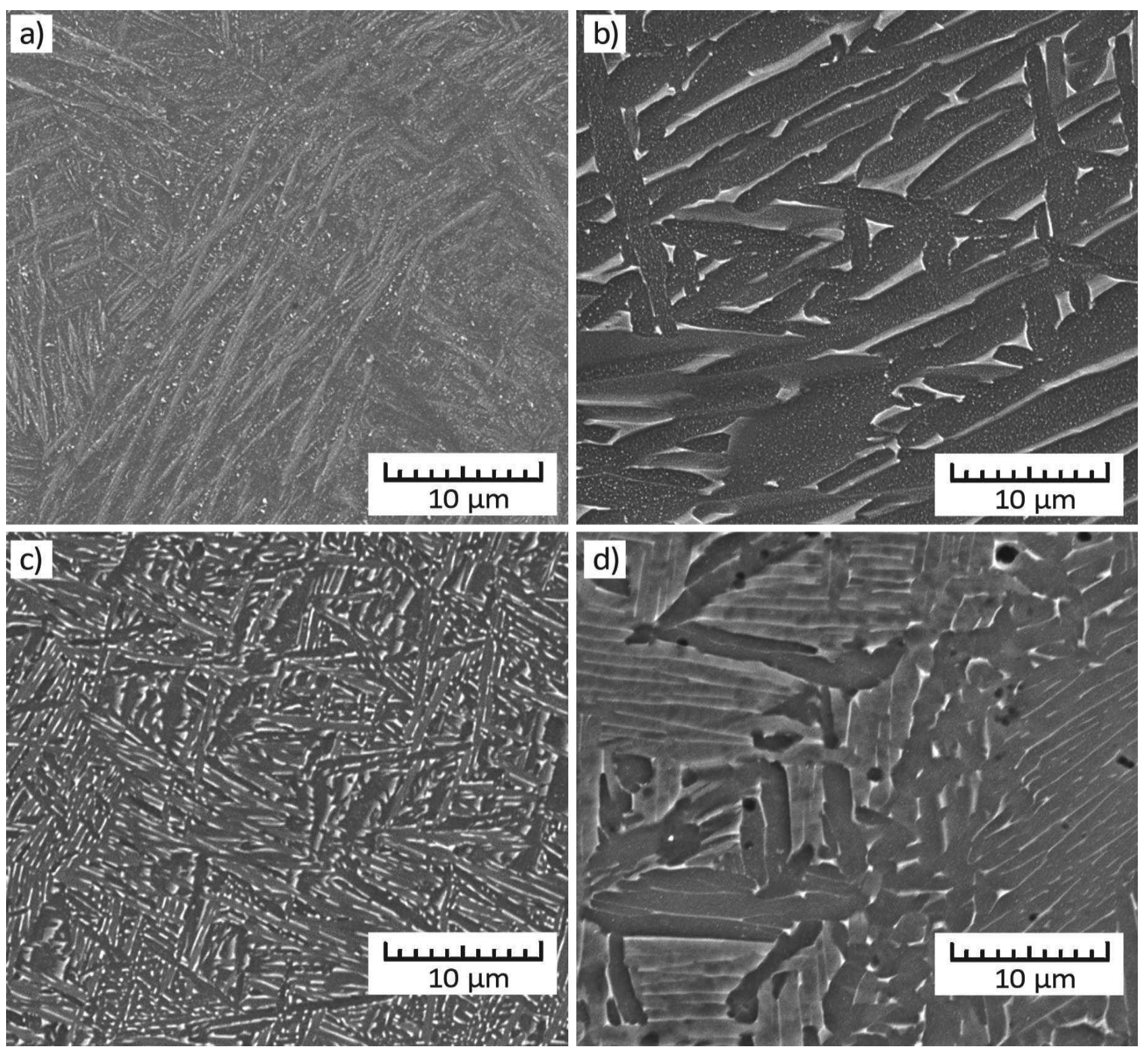

Fig. 1 SEM images of Ti6 Al4V alloy: (a) SLM, (b) SLM-HIP, (c) EBM, (d) bot-worked

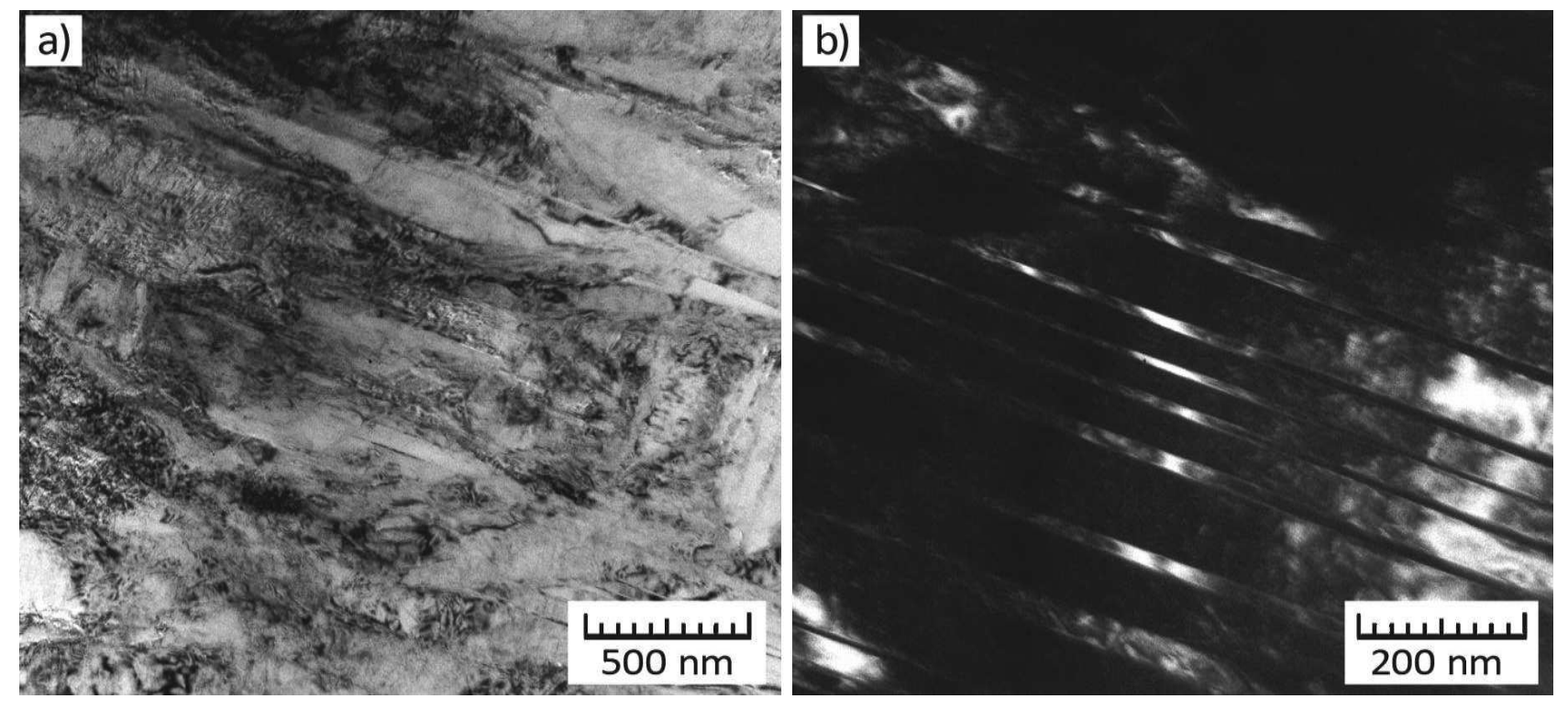



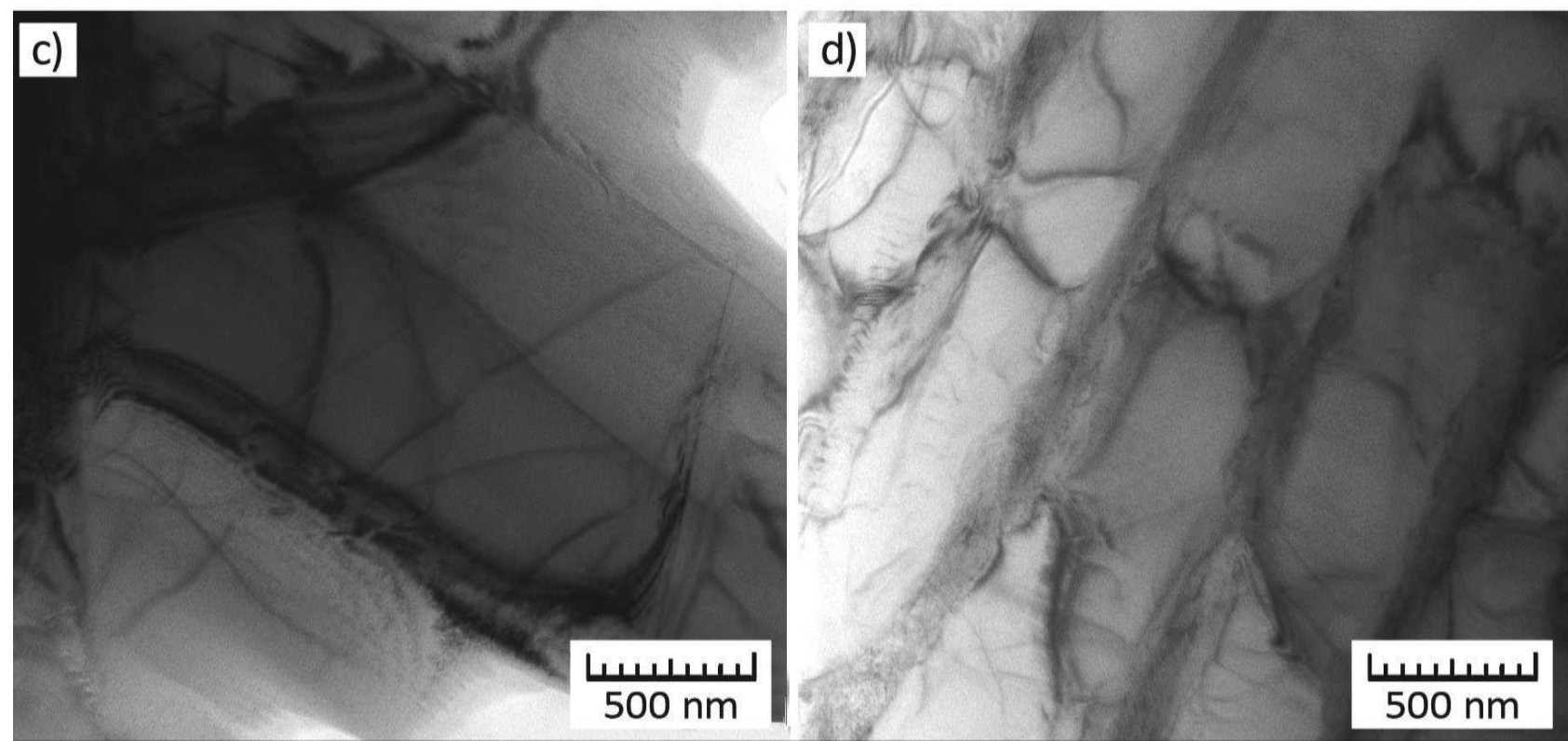

Fig. 2TEM images of Ti6 Al4V alloy: (a-b) SLM, (c) SLM-HIP, (d) EBM
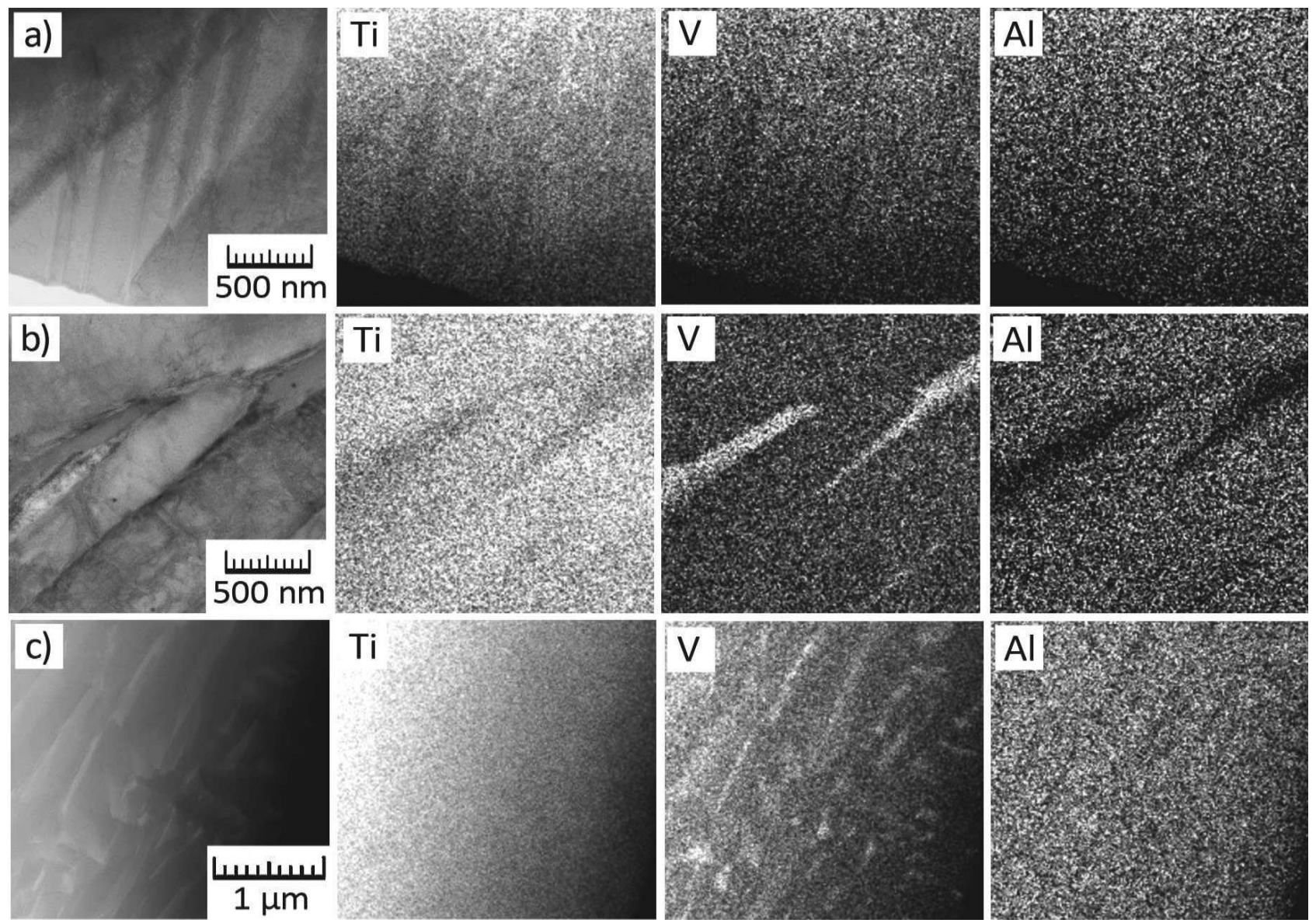

Fig. 3 TEM-EDS maps of element distribution in TiAl6V4 alloy: (a) SLM, (b) SLM-HIP, (c) EBM

Measured XRD spectra were subjected to Williamson-Hall calculation to determine the level of internal strain and size of crystallites (coherently diffracting domains which might be associated with subgrains) [21]:

$$
B \cdot \cos \theta=k \cdot \lambda \cdot d^{-1}+4 \varepsilon \cdot \sin \theta,
$$

where $B$ - peak broadening

$\theta-$ a diffraction angle

$k-$ a constant

$d$ - the crystallite size

$\lambda$ - the wavelength of the used $\mathrm{X}$-ray radiation (here $\lambda_{\mathrm{Co}_{\mathrm{o}}}=0.179 \mathrm{~nm}$ )

$$
\varepsilon \text {-strain }
$$


The results of this calculation for all studied materials are given in Table 1 . The highest strain was detected in the as-built SLM state, which was significantly reduced by HIP. Only slightly more strain remained in the material after the EBM processing.

Tab. 1 Crystallite size and internal strain calculated from eq. 2

\begin{tabular}{|c|c|c|c|c|}
\hline & SLM & SLM-HIP & EBM & hot-worked \\
\hline $\mathrm{d}(\mathrm{nm})$ & 75 & 88 & 56 & $>250$ \\
\hline$\varepsilon(\%)$ & 0.95 & 0.12 & 0.20 & 0.05 \\
\hline
\end{tabular}

\subsection{Hardness and wear rate}

The bar chart in Fig. 4a demonstrates that refining the microstructure and bringing residual stresses enhances the hardness of additively manufactured Ti6Al4V alloy in comparison with the conventionally prepared alloy. The highest hardness of the SLMTi6Al4V can be attributed to martensitic microstructure although it is not so much higher compared to the EBM-alloy. That is because only a mild distortion occurs in the hcp crystal lattice with $\mathrm{V}$ oversaturation [15]. A drop in hardness is registered after HIP due to microstructure coarsening by transformation of $\alpha^{\prime}$ needles to $\alpha$ lamellae (Fig. 1) and significant relief of high residual stresses (Table 1). But still, the hardness of the conventional hot-worked alloy is exceeded. Hardness of EBM material is somewhat higher than that of SLM-HIP, in accordance with its lower lamellae size and slightly higher level of internal stresses (Table 1). However, the contribution of refinement is limited by the opposite effect of the increased content of the softer $\beta$-phase.

Figure $4 \mathrm{~b}$ then shows the comparison between
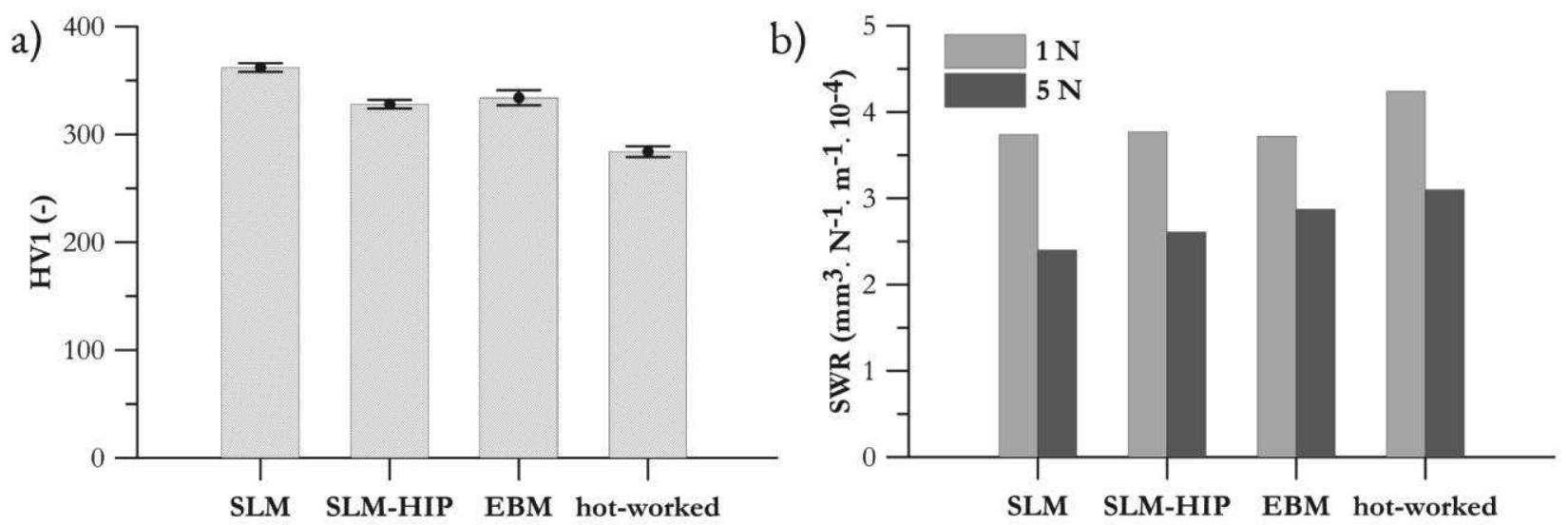

Fig. 4 Hardness (a) and specific wear rate (b) of the studied states of Ti6Al4V alloy

Tab. 2 Mean values of friction coefficient between the Ti6 Al4 V/ $\mathrm{Al}_{2} \mathrm{O}_{3}$ wear pair

\begin{tabular}{|c|c|c|c|c|}
\hline \multicolumn{5}{|c|}{ Mean friction coefficient $f(-)$} \\
\hline $\mathrm{F}_{\mathrm{N}}$ & SLM & SLM-HIP & EBM & hot-worked \\
\hline $1 \mathrm{~N}$ & 0.453 & 0.463 & 0.461 & 0.472 \\
\hline $5 \mathrm{~N}$ & 0.407 & 0.433 & 0.434 & 0.438 \\
\hline
\end{tabular}

specific wear rates of the Ti6Al4V alloy in different production forms. The chart for the lower normal load of $1 \mathrm{~N}$ demonstrates that AM generally decreases SWR, thus improves the resistance of the material to wear. There are no significant differences between different AM processing routes. Only after increasing the normal load to $5 \mathrm{~N}$, slightly variable microstructural features come to light. Generally, the trend in SWR agrees well with the Archard law which describes the volumetric loss being inversely proportional to hardness [22]. However, the EBM sample slightly deviates from this trend. The explanation might be based on the hypothesis that lower lamellae size together with a higher content of softer $\beta$-phase intensifies material removal by abrasion. Abrasive wear mechanism was clearly documented by SEM images of wear tracks (exemplar wear track for SLM-HIP sample shown in Fig. 5) where grooves were visible in the direction of reciprocal movement of the wear pair. Also signs of adhesion wear were visible in the wear tracks of SLMHIP, EBM and hot-worked samples which contain deformable $\beta$-phase.

For higher normal load, SWR dropped. That can be explained by increased heat production during friction and intensified surface oxidation - hard oxide layer improves sliding properties and decreases friction coefficient (see Table 2). BSE images in Fig. 5 show the comparison in the oxidation occurring during testing at $1 \mathrm{~N}$ and $5 \mathrm{~N}$ load. Extensive oxidation and released oxidized particles after the wear test with higher load are confirmed by EDS maps (Fig. 5b). Abrasive wear is more pronounced due to higher amount of released oxide particles which are harder than the matrix and so intensify the abrasion. 


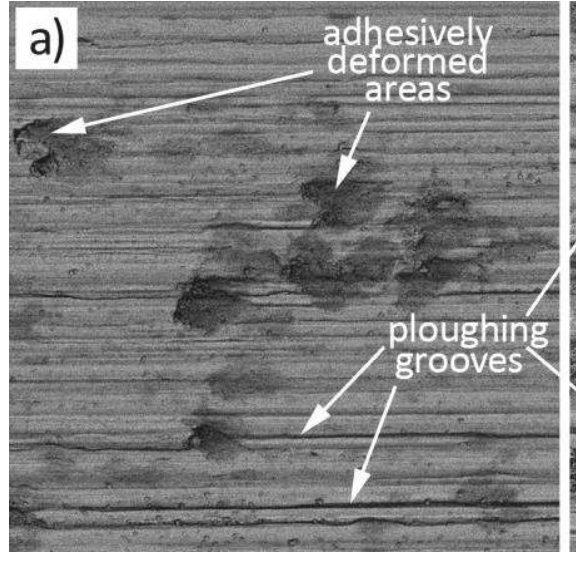

Fig. 5 BSE images showing the appearance
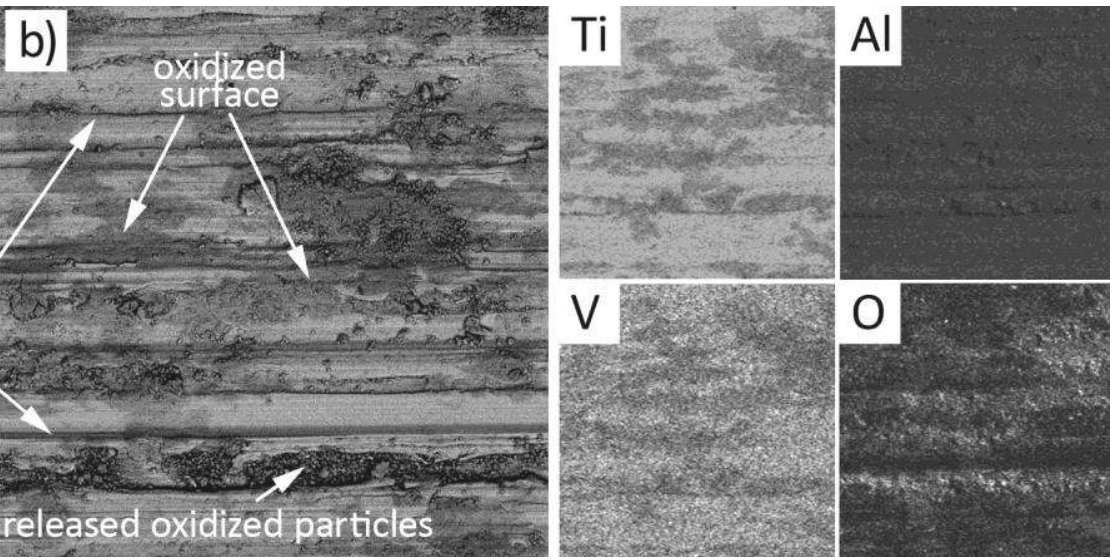

ED and features of wear tracks (SLM-HIP samp showing the presence of oxides
EDS maps

\section{Conclusion}

The tribology characterization presented in this paper has shown that additive manufacturing does not adversely affect the wear resistance of Ti6Al4V biomedical alloy neither improves it significantly. Refined microstructures and residual stresses brought about by AM slightly reduced the specific wear rate, although it has still remained rather poor. Differences between differently processed samples have not manifested themselves before increasing the test load to $5 \mathrm{~N}$. Then the specific wear rate showed to be dependent on the hardness value, size of microstructural features and content of $\beta$-phase. The hardest SLM sample with the fully martensitic microstructure composed of fine $\alpha$ needles showed the lowest SWR. Despite its high hardness, the EBM sample was characterized by the highest SWR compared to other additively manufactured samples, probably due to the highest content of soft $\beta$-phase and very fine lamellar microstructure. HIP did not significantly increase the SWR of the SLM sample although it yielded phase transformation, significant microstructure coarsening and reduced residual stresses. The observed wear was of an oxidative character.

\section{Acknowledgement}

The authors wish to thank the Ministry of Education, Youth and Sports for the financial support of this research (specific university research, project no. A1_FCHT_2020_003). The authors also acknowledge the assistance in TEM sample preparation provided by the Research Infrastructure NanoEnviCz, supported by the Ministry of Education, Youth, and Sports of the Czech Republic under Project No. LM2015073.

\section{References}

[1] DONG, H. (2010). Chapter 3 - Tribological properties of titanium-based alloys, in Surface
Engineering of Light Alloys, pp. 58-80. Woodhead Publishing. ISBN 978-1-84569-537-8.

[2] WANG, X., XU, S., ZHOU, S., XU, W., LEARY, M., CHOONG, P., QIAN, M., BRANDT, M., XIE, Y. M. (2016). Topological design and additive manufacturing of porous metals for bone scaffolds and orthopaedic implants: A review. In: Biomaterials, Vol. 83, pp. 127-141.

[3] HUSSEIN, M. A., MOHAMMED, A. S., ALAQEELI, N. (2015). Wear Characteristics of Metallic Biomaterials: A Review. In: Materials, Vol. 8, No. 5, pp. 2749-2768.

[4] CHOUBEY, A., BASU, B., BALASUBRAMANIAM, R. (2004). Tribological behaviour of Ti-based alloys in simulated body fluid solution at fretting contacts. In: Materials Science and Engineering: $A$, Vol. 379, No. 1, pp. 234-239.

[5] CVIJOVIĆ-ALAGIĆ, I., CVIJOVIĆ, Z., MITROVIĆ, S., RAKIN, M., VELJOVIĆ, Đ., BABIĆ, M. (2010). Tribological Behaviour of Orthopaedic Ti-13Nb-13Zr and Ti-6Al-4V Alloys. In: Tribology Letters, Vol. 40, No. 1, pp. 59-70.

[6] LONG, M., RACK, H. J. (2001). Friction and surface behavior of selected titanium alloys during reciprocating-sliding motion. In: Wear, Vol. 249, No. 1, pp. 157-167.

[7] SURESH, K. S., GEETHA, M., RICHARD, C., LANDOULSI, J., RAMASAWMY, H., SUWAS, S., ASOKAMANI, R. (2012). Effect of equal channel angular extrusion on wear and corrosion behavior of the orthopedic Ti$13 \mathrm{Nb}-13 \mathrm{Zr}$ alloy in simulated body fluid. In: Materials Science and Engineering: C, Vol. 32, No. 4, pp. 763-771. 
[8] GORSSE, S., HUTCHINSON, C., GOUNÉ, M., BANERJEE, R. (2017). Additive manufacturing of metals: a brief review of the characteristic microstructures and properties of steels, Ti-6Al-4V and high-entropy alloys. In: Science and technology of advanced materials, Vol. 18, No. 1, pp. 584-610.

[9] FOUSOVA, M., DVORSKY, D., VOJTECH, D. (2017). Additively manufactured aluminium AlSi10Mg alloy. In: Manufacturing Technology, Vol. 17, No. 4, pp. 446-451.

[10] KRISTOFOVA, P., KUBASEK, J., VOJTECH, D., PALOUSEK, D., SUCHY, J. (2019). Microstructure of the Mg-4Y-3RE-Zr (WE43) Magnesium Alloy Produced by 3D Printing. In: Manufacturing Technology, Vol. 19, No. 1, pp. 89-94.

[11] ASTM F136-13, Standard Specification for Wrought Titanium-6Aluminum-4V anadium ELI (Extra Low Interstitial) Alloy for Surgical Implant Applications (UNS R56401).

[12] ROUDNICKA, M., MISURAK, M., VOJTECH, D. (2019). Differences in the response of additively manufactured titanium alloy to heat treatment-Comparison between SLM and EBM. In: Manufacturing Technology, Vol. 19, No. 4, pp. 668-673.

[13] ROUDNICKA, M., MERTOVA, K., VOJTECH, D. (2019). Influence of hot isostatic pressing on mechanical response of asbuilt SLM titanium alloy. In: IOP Conference Series: Materials Science and Engineering, Vol. 629, pp. 012034.

[14] SHAIKH, A., KUMAR, S., DAWARI, A., KIRWAI, S., PATIL, A., SINGH, R. (2019). Effect of Temperature and Cooling Rates on the $\alpha+\beta$ Morphology of Ti-6Al-4V Alloy. In: Procedia Structural Integrity, Vol. 14, pp. 782-789.

[15] MOTYKA, M., BARAN-SADLEJA, A., SIENIAWSKI, J., WIERZBINSKA, M., GANCARCZYK, K. (2019). Decomposition of deformed $\alpha^{\prime}\left(\alpha^{\prime \prime}\right)$ martensitic phase in Ti-
6Al-4V alloy. In: Materials Science and Technology, Vol. 35, No. 3, pp. 260-272.

[16] DONACHIE, M. J. (2000) Titanium: A Technical Guide, 2nd ed. ASM International, Russell Township.

[17] GU, D., HAGEDORN, Y.-C., MEINERS, W., MENG, G., BATISTA, R. J. S., WISSENBACH, K., POPRAWE, R. (2012). Densification behavior, microstructure evolution, and wear performance of selective laser melting processed commercially pure titanium. In: Acta Materialia, Vol. 60, No. 9, pp. 3849-3860.

[18] ANTONYSAMY, A. A., MEYER, J., PRANGNELL, P. B. (2013). Effect of build geometry on the $\beta$-grain structure and texture in additive manufacture of Ti6Al4V by selective electron beam melting. In: Materials Characterization, Vol. 84, pp. 153-168.

[19] LIU, S., SHIN, Y. C. (2019). Additive manufacturing of Ti6Al4V alloy: A review. In: Materials \& Design, Vol. 164, pp. 107552.

[20] BENEDETTI, M., TORRESANI, E., LEONI, M., FONTANARI, V., BANDINI, M., PEDERZOLLI, C., POTRICH, C. (2017). The effect of post-sintering treatments on the fatigue and biological behavior of Ti-6Al-4V ELI parts made by selective laser melting. In: Journal of the Mechanical Behavior of Biomedical Materials, Vol. 71, pp. 295-306.

[21] KHORSAND ZAK, A., ABD. MAJID, W. H., ABRISHAMI, M. E., YOUSEFI, R. (2011). Xray analysis of $\mathrm{ZnO}$ nanoparticles by Williamson-Hall and size-strain plot methods. In: Solid State Sciences, Vol. 13, No. 1, pp. 251256.

[22] LIU, Y., LISKIEWICZ, T. W., BEAKE, B. D. (2019). Dynamic changes of mechanical properties induced by friction in the Archard wear model. In: Wear, Vol. 428-429, pp. 366375. 